\title{
CIUDADANÍA POSTNACIONAL. DERECHOS POLÍTICOS DE LOS INMIGRANTES LATINOAMERICANOS EN ESPAÑA
}

\author{
POSTNATIONAL CITIZENSHIP. POLITICAL RIGHTS OF LATIN-AMERICAN \\ IMMIGRANTS IN SPAIN
}

\author{
Yolanda Carmela Vaccaro Alexander \\ Universidad CEU San Pablo. Madrid. España/Spain \\ yvaccaro@yahoo.com
}

Recibido/Received: 21/04/2017

Modificado/Modified: 14/07/20177

Aceptado/Accepted: 10/10/2017

\section{RESUMEN}

La ciudadanía postnacional tal como es descrita por Jürgen Habermas es la alternativa viable frente a los conceptos clásicos que vinculaban necesariamente ciudadanía con nacionalidad y los conceptos aperturistas que abogan por una ciudadanía universal. Mientras las formulaciones clásicas han quedado desfasadas en un mundo globalizado y donde las migraciones son un hecho, la idea de ciudadanía cosmopolita resulta hasta cierto punto quimérica. Habermas aplica el concepto de ciudadanía postnacional al hablar de la ciudadanía europea. De la misma forma el concepto se puede aplicar a la relación que existe entre España y la mayor parte de países de Latinoamérica en cuanto a legislación que permite extender la ciudadanía española entre inmigrantes latinoamericanos residentes en España así como sucede en los correspondientes países latinoamericanos respecto de los residentes españoles, configurándose lo que bien puede considerarse una ciudadanía iberoamericana. La extensión del derecho de sufragio es la prueba más palpable de ello.

\section{PALABRAS CLAVE}

Derechos políticos; derecho de sufragio; inmigración; ciudadanía iberoamericana; integración.

\section{SUMARIO}

1. Introducción y objetivos de la investigación. 2. Evolución del concepto de ciudadanía. 3. Ciudadanía postnacional. 4. Debate sobre la titularidad de los derechos políticos por parte de los inmigrantes y la idea de ciudadanía. 5. Ciudadanía iberoamericana y extensión del derecho de sufragio. 6. Conclusiones. Bibliografía.

\footnotetext{
ABSTRACT

Post-national citizenship, as it is described by Jürgen Habermas, is the viable alternative that exists between the classical concepts, that necessarily link citizenship with nationality, and the open-minded concepts, that advocate a cosmopolitan, universal citizenship. While the classical concepts have become outdated by the development of a globalized world and where migrations are a fact, the concept of cosmopolitan citizenship is somewhat chimerical. Habermas applies the concept of post-national citizenship when talking about European citizenship; the concept can be applied to the relationship between Spain and most Latin American countries in terms of legislation which allows Spanish
} 
citizenship to be extended to Latin American immigrants living in Spain, as well as in the corresponding Latin American countries with respect to Spanish residents, forming what can well be considered as an Ibero-American Citizenship. The extension of the right of suffrage is the most palpable proof of this.

\section{KEYWORDS}

Political Rights; Right of Suffrage; Immigration; Ibero- American Citizenship; Integration.

\section{CONTENTS}

1. Introduction and research's objectives. 2. Evolution of the concept of citizenship. 3. Post-national citizenship. 4. Debate about political rights of immigrants and the idea of citizenship. 5. IberoAmerican Citizenship and extension of the right to vote. 6. Conclusions. References.

\section{INTRODUCCIÓN Y OBJETIVOS DE LA INVESTIGACIÓN}

El reconocimiento de la titularidad y el ejercicio del derecho de sufragio para los inmigrantes es la prueba práctica más relevante y palpable de que los conceptos de ciudadanía y nacionalidad han evolucionado y tomado caminos diversos en los diferentes Estados. Si bien Jürgen Habermas considera que la ciudadanía nunca ha estado conceptualmente ligada a la identidad nacional (Heater, 2007: 162; Habermas, 2010), en los últimos dos siglos ambos conceptos han marchado de la mano en la práctica. En la actualidad cada vez son más numerosos los Estados que reconocen (o conceden) el derecho de sufragio a personas que residen en sus territorios sin que éstas hayan adoptado la nacionalidad del país anfitrión. El concepto de ciudadanía pierde cada vez más su tradicional vinculación con el de nacionalidad. Y se configura así en la práctica la idea de ciudadanía postnacional de la que la ciudadanía europea es el mejor ejemplo.

Desde mediados del siglo pasado, España y la mayor parte de países latinoamericanos vienen suscribiendo convenios y acuerdos que conceden ventajas para los nacionales de ambos países: para los latinoamericanos de dichos países que residen en España y para los españoles que viven en tales países de Latinoamérica. Los primeros acuerdos se refieren a la doble nacionalidad, suscritos desde la década de 1950. Asimismo, desde 2009, en aplicación del artículo 13 de la Constitución Española (CE), España ha suscrito acuerdos de reciprocidad en materia de sufragio en comicios locales con diversos países, siendo la mayor parte de ellos latinoamericanos: Bolivia, Chile, Colombia, Ecuador, Paraguay y Perú.

El espíritu de la legislación española señala que merced a los lazos históricos y culturales existentes entre ambas orillas del Atlántico, los latinoamericanos en España cuentan con mayores facilidades de adaptación e integración en el marco jurídico y social respecto de inmigrantes de otras procedencias. De igual manera, y por reciprocidad en la mayoría de los casos, los españoles residentes en los correspondientes países latinoamericanos cuentan con tales ventajas. Esta situación estaría configurando una ciudadanía iberoamericana a la manera como es definida la ciudadanía postnacional principalmente por Habermas, tal como sucede con la ciudadanía europea.

En cuanto al análisis por parte de los expertos en la materia, no hay acuerdo sobre la conveniencia o la justicia de tal preferencia. Así, hay autores que defienden la validez y la legitimidad de esta situación en cierto modo privilegiada, como Izquierdo et al. (2010), que consideran que la sociedad española, por diversos motivos, prefiere que el colectivo inmigrante a gran escala esté formado sobre todo por inmigrantes latinoamericanos, algo que 
se ve reflejado en la correspondiente legislación. Sin embargo, otros estudiosos del tema discrepan. Tal es el caso de Moya y Viñas (2010), que opinan que al favorecer a los latinoamericanos respecto de otros colectivos se estaría creando una brecha que separa a los inmigrantes. En este trabajo se analiza el tema desde una perspectiva de hecho. Es decir, como una realidad que existe en la legislación española desde hace varias décadas.

El primer objetivo de este trabajo es analizar la evolución de los conceptos de ciudadanía y ciudadanía postnacional principalmente desde la perspectiva del análisis elaborado sobre la materia por Habermas.

El segundo objetivo es abordar el debate sobre la pertinencia de reconocer derechos políticos a los inmigrantes, particularmente el derecho de sufragio, y su relación con el concepto contemporáneo de ciudadanía.

El tercer objetivo es analizar el ejemplo de la aplicación de la ciudadanía postnacional a través del reconocimiento del derecho de sufragio de los residentes latinoamericanos en España.

\section{EVOLUCIÓN DEL CONCEPTO DE CIUDADANÍA}

La relación entre los conceptos de ciudadanía y nacionalidad resulta fundamental a la hora de abordar el estatus jurídico y legal de los inmigrantes en general y de los inmigrantes residentes en España en particular. Abordar la relación entre los conceptos de ciudadanía y nacionalidad es incluso inevitable al tratar el estatus jurídico, legal y sociológico de los inmigrantes tal como señala Martínez de Pisón (2004) al indicar que los derechos de los inmigrantes "derivarían de los derechos de la ciudadanía".

Asimismo, el concepto vertebra las sociedades actuales y, naturalmente, enmarca el reconocimiento de los derechos de los ciudadanos. La propia definición de sociedad está enlazada con este concepto pues el hombre, parafraseando a Aristóteles (384 - 322 a.C.), debe vivir en comunidad (Horrach, 2009: 1). Aristóteles, considerado el primer pensador en formular una tesis completa sobre ciudadanía, definió que esta "supone una cierta comunidad". Para el célebre filósofo, quien no sabe vivir en sociedad "es una bestia o un dios" (Aristóteles, 2000).

A grandes rasgos desde sus inicios, tal como se evidencia en los albores de Roma y Grecia, la ciudadanía ha estado unida a concepciones excluyentes. Uribe Otalora, A. (2010: 42) recuerda que para los romanos "la dignitas era una cualidad exclusiva de colectivos sociales concretos: nobles, magistrados y sacerdotes". Según la teoría clásica solo podían ser considerados ciudadanos los miembros de la sociedad que cumplían una serie de requisitos: pertenecer a una determinada clase social (alta), ser varones y propietarios, en líneas generales. En este orden de cosas solo los ciudadanos podían ser titulares de derechos, incluido el derecho al voto. A partir de la Grecia clásica y de Roma la ciudadanía "fue evolucionando como estatus privilegiado de un grupo limitado de hombres en algunas ciudades europeas" (Giner, S. et al. 1998: 107).

Las raíces grecorromanas del concepto de ciudadanía se hunden, en efecto, en la Edad Antigua. Los griegos acuñan el término pero son los romanos quienes le dan un contorno extensivo en su imperio tanto por la magnitud de su territorio como por la ampliación de la denominación de ciudadanos entre las poblaciones conquistadas si bien, claro está, con las conocidas excepciones que se extenderían incluso hasta el S. XX.

Si bien en 1642, en su obra Elementos filosóficos del ciudadano (2000), Thomas Hobbes plantea una descripción del concepto esencial del ciudadano moderno, no será sino hasta las 
revoluciones, americana y francesa, cuando la idea cobre su auténtica dimensión moderna. Asimismo, es en el S. XVIII cuando empieza a identificarse ciudadanía con nación, algo de lo que fueron gestores clave las revoluciones Francesa y Americana. Y es que ambas revoluciones encontraron en la idea de la nación y en componentes emocionales como el "amor a la patria" uno de sus ejes. Sin embargo, mientras la "nación francesa" estaba anclada y distinguida notoriamente por la historia, el caso americano supone una idea nueva pues se trata de una nación que empieza a formarse y que, integrada por personas de diversa procedencia, da paso a la idea de una ciudadanía nacional más abierta (Horrach, 2009: 13), un elemento destacable de los conceptos actuales de ciudadanía más allá de la nacionalidad.

En este contexto la definición de ciudadanía se conceptualiza de forma sistemática en el S. XX. La teoría clásica contemporánea está enraizada básicamente como punto de inflexión en "Ciudadanía y clase social", la célebre conferencia de Thomas H. Marshall pronunciada en 1950 que diferencia los estadios de la ciudadanía conforme al reconocimiento de los derechos sociales, civiles y políticos. No obstante, por su contexto histórico, de mediados del siglo pasado, y geográfico, circunscrito a Inglaterra, la definición que hace Marshall (1997) sobre ciudadanía ha quedado superada por el acontecer histórico y legal de las últimas décadas, particularmente por los conceptos de ciudadanía emanados de bloques geográficos como el de la UE. Con todo, Marshall trazó los elementos básicos de ciudadanía que hoy utilizamos.

Los grandes cambios económicos, políticos, tecnológicos y sociales de las últimas décadas, fruto del proceso de globalización del que forman parte todos los países, al margen de su estatus de desarrollo, han provocado una apertura en el replanteamiento de conceptos que para algunos no admitían modificación por ser considerados durante mucho tiempo elementos intrínsecos de los Estados y garantes del ejercicio del poder en todas sus dimensiones.

Así tenemos que con la evolución social y temporal la ciudadanía empieza a incluir a otros miembros de la sociedad más allá de los varones propietarios. Primero incluye a los integrantes de clases sociales más numerosas al margen de que sus integrantes tuvieran o no la condición de propietarios. Posteriormente se incluye a las mujeres. En consecuencia, miembros de la sociedad que estuvieron marginados del derecho político por antonomasia empiezan a ser considerados como titulares del derecho de sufragio, que empiezan a ejercer. La evolución social, con sus diversos matices dependiendo de los países, regiones y culturas, genera que el pensamiento común poco a poco empiece a considerar como obvio algo que tardó mucho en hacerse realidad: son ciudadanos todos los integrantes de una sociedad, al menos de un Estado.

En este escenario coexisten en el mundo contemporáneo diversas teorías y modelos de ciudadanía desembocando en lo que se considera ciudadanía cosmopolita, universal, un modelo que, según la óptica de autores contemporáneos, postula incluso que cada ciudadano sea responsable y se inmiscuya en la esfera pública, política (Güell, 2012: 12).

En los tiempos actuales tenemos que la ciudadanía, en aspectos fundamentales y en un creciente número de Estados, incluye también a no nacionales, inmigrantes residentes en un país determinado que empiezan a ser titulares de derechos políticos y a ejercer el derecho de sufragio. El primer paso suele ser el reconocimiento de tal derecho para los inmigrantes en elecciones en el ámbito local. En la Unión Europea (UE) el punto de partida es el Tratado de Maastricht (Unión Europea, 1992), que alumbra el concepto de "ciudadanía de la Unión Europea (UE)" a partir del cual los nacionales de la UE residentes en países de la UE que no son el propio pueden ejercer el derecho de sufragio en comicios locales y para elegir a los integrantes del Parlamento Europeo. 


\section{CIUDADANÍA POSTNACIONAL}

Para Habermas, la reunificación alemana, la desmembración de la Unión Soviética, los conflictos nacionales surgidos en Europa del Este, el desarrollo de la Comunidad Europea, los flujos migratorios y de refugiados son movimientos que han afectado especialmente "la relación entre ciudadanía e identidad nacional” (Habermas, 2010: 619- 620). En el mundo de hoy, merced a las migraciones y a sus esquemas derivados como el multiculturalismo, el concepto de nacionalidad es superado por el de ciudadanía. Habermas considera válida la manifestación de Thadden de que es "urgente" retornar "a la idea de citoyen" porque es "mucho más abierta y mucho menos rígida que la tradicional idea de nacionalidad en el sentido de pertenencia a una nación" (Habermas, 2010: 592). Recuerda que en el lenguaje de los juristas "ciudadanía" tuvo durante mucho tiempo solo el sentido de pertenencia a un Estado o de nacionalidad y que "solo recientemente ha sido ampliado el concepto en el sentido de un estatus de ciudadano, circunscrito por los derechos civiles". Así, pues, las expresiones de ciudadanía ya no se emplean solo para denotar la pertenencia a una organización estatal sino también "para significar el status que, en lo que a contenido se refiere, viene definido por los derechos y deberes ciudadanos" (Habermas, 2010: 624- 625). La reformulación teórica y práctica de los conceptos de ciudadanía, nacionalidad y Estado, que quedan desbordados por el acontecer propio de las sociedades principalmente con las oleadas migratorias, conlleva la interconexión de sociedades y culturas que, gracias a la mundialización, en el sentido más integral del término, implica variaciones en el ejercicio de los derechos civiles y políticos por a la migración de millones de personas que, por distintas causas, deciden establecerse en un lugar distinto al de su nacimiento. Es decir, estamos ante una conceptualización cosmopolita de los términos ciudadanía y nacionalidad de cara al nuevo orden global. Horrach (2009) habla de lo que se puede considerar como una "ciudadanía universal" que "trasciende diferencias nacionales, religiosas o culturales".

En este escenario la extensión de derechos políticos y, entre ellos, el derecho de sufragio, es una prueba palmaria de que la ligazón entre nacionalidad y ciudadanía se debilita jalonada por los flujos migratorios que reformulan la configuración de los Estados. Así, para Durán A. (2015: 86), "anudar" nacionalidad y ciudadanía de modo que solo el "ciudadano- nacional" tiene derecho a elegir y ser elegido a sus representantes políticos es "una secuencia que ha ido perdiendo racionalidad" y que "exige una reformulación más adaptada a los tiempos".

Diversos analistas, en esta línea, sostienen que el proceso de integración de los inmigrantes debe ampliarse a las esferas políticas, permitiéndoseles la participación en la toma de decisiones. El mejor ejemplo sería el hecho de que en diferentes Estados se reconoce que los inmigrantes tienen derecho al sufragio -en determinadas circunstancias y con diferentes condiciones- aun cuando no posean el estatus de nacionales. Al respecto, Santolaya y Díaz (2008: 12-13) proponen que los conceptos nacionalidad y ciudadanía coinciden en que se trata en ambos casos de tener poder de decisión y que los inmigrantes formen parte de las instancias representativas.

En esta línea de pensamiento se pronuncia Uribe Otalora (2010: 39), cuando habla de una "vulnerabilidad" de los inmigrantes en la UE, indicando que los inmigrantes "como colectivo vulnerable, suelen tener cercenados algunos derechos fundamentales, entre los que se sitúan los derechos políticos". La autora resalta que hay una vinculación elemental entre ciudadanía y derecho al sufragio apuntando que "es habitual que el derecho al voto esté vinculado a los nacionales de un país y, de forma excepcional a los extranjeros". Este hecho, indica, "reduce la ciudadanía básicamente al colectivo de individuos que disfrutan de la nacionalidad de un país determinado". En este aspecto Rodríguez Ruiz (2015: 52) apunta que nada impide la 
apertura de la participación política a población extranjera (inmigrante) "salvo la reducción de la ciudadanía a su dimensión formal, como mero sinónimo de nacionalidad".

En este marco, si bien el debate sobre la relación entre ciudadanía y nacionalidad sigue siendo recurrente (Uribe Otalora, 2010: 57) ambas ideas han pasado de estar unidas de forma casi indisoluble a ser conceptos que en las sociedades contemporáneas se deslindan claramente siendo la participación política una de sus más recientes plasmaciones, sin duda la más relevante. Una idea que ya defendió Ernest Renan (1987: 83) en el S. XIX. Tras refutar impecablemente los argumentos sobre religión o lengua para determinar qué es una nación, Renan subraya que una nación es "una gran solidaridad" y "un plebiscito de todos los días del mismo modo que la existencia del individuo es una perpetua afirmación de la vida". Afirmaciones que perfectamente pueden enmarcarse como el preludio de las teorías aperturistas de nuestros días.

Como contraposición a la idea tradicional que vincula ciudadanía con pertenencia a un Estado, el cosmopolitismo universal se erige como la respuesta natural, con inspiración en el ideal de "La paz perpetua" de Kant (2003). Kant defiende un sistema global de derechos y deberes universal, más allá del lugar de nacimiento o de residencia de los individuos; en "La paz perpetua" señala que la realización de la idea de un orden cosmopolita es la única vía para que no haya guerras que, mediante una constitución común, resultan ilegales.

Partiendo de la base de la idea kantiana, Habermas, sin embargo, desarrolla un modelo mucho más viable al menos en nuestros días: la creación de federaciones de Estados que configuran ciudadanías postnacionales, siendo el caso de la ciudadanía europea el más emblemático del paradigma. En efecto, Habermas parte de la defensa de una sociedad cosmopolita recordando que el nacimiento del Estado nacional como producto de la Revolución Francesa "tuvo en su origen un sentido completamente universalista", un "elemento cosmopolita" que, señala, "habría que reactivar y desarrollar hoy en el sentido de un multiculturalismo" (Habermas, 2007: 117-118). Lo interesante es que Habermas completa este pensamiento añadiendo que "la vinculación a los principios del Estado de Derecho y de la democracia" solo cristaliza en las distintas naciones "si esos principios echan raíces en las diversas culturas políticas que serán distintas en cada una de ellas". El contenido "universalista", explica, "habrá de ser en cada caso asumido desde el propio contexto histórico y quedar anclado en las propias formas culturales de vida". Abunda: "Toda identidad colectiva, también la postnacional, es mucho más concreta que el conjunto de principios morales, jurídicos y políticos en torno a los que cristaliza" (Habermas, 2007: 118-119).

Habermas anota que "la sociedad política mundial se compone en nuestros días de Estados nacionales" subrayando que "aquel tipo histórico que resultó de la Revolución Francesa y de la Revolución Americana se ha implantado a lo largo y ancho del planeta". En la actualidad, añade, "el Estado nacional ha logrado imponerse frente a las antiguas formaciones políticas". No obstante, advierte que los desafíos de la sociedad actual "ya no pueden solucionarse dentro del marco de un Estado nacional o por las vías de los Estados soberanos". Habermas realizó estas apreciaciones en 1996, fecha de publicación de la primera edición, en su alemán natal, de "La inclusión del otro", anotando que la situación actual estaba dando paso a estructuras supranacionales diferentes a la de Naciones Unidas como la ya para entonces bastante cimentada Comunidad Europea así como las entonces germinales estructuras supranacionales en América del Norte y en Asia. Paradójicamente, continúa, "las prestaciones integradoras del Estado nacional" son el primer gran ejemplo de la formación de estructuras que abarcan conglomerados más allá de pueblos o tribus. Así, el "camino hacia las sociedades postnacionales" se puede graficar siguiendo el modelo de aquella forma histórica que estamos en actitud de superar", es decir, el Estado nacional (Habermas, 1999: 81- 83). En 1998, 
Habermas apunta que "el plano de integración que representa el Estado está perdiendo hoy cada vez más competencias bajo la presión de los movimientos regionales" así como bajo el influjo "de las empresas y organizaciones supraestatales que operan a nivel mundial". El Estado nacional producto de la Revolución Francesa, indica, fue el modelo de "la última generación de Estados, la surgida de la descolonización” esquema al que, sin embargo, considera Habermas, "nunca se ajustaron" ni Estados Unidos ni la extinta Unión Soviética con sus "sociedades multinacionales". Sentencia que "para los herederos actuales del sistema de Estados europeos" el nacionalismo ha "perdido atractivo" por lo que tales Estados "se encuentran en vías de convertirse en sociedades postnacionales" (Habermas, 2010: 591). El desarrollo de la UE hacia una unión política, en el marco de una "disolución de las ligaduras semánticas entre ciudadanía e identidad nacional", es el ejemplo palmario de que "la forma clásica del Estado nacional se encuentra en disolución” (Habermas, 2010: 620- 621).

Para Habermas la "soberanía exterior de los Estados" se ha convertido en "un anacronismo" a la vista de "las coacciones y los imperativos del mercado mundial" y "de la planetaria densificación de la comunicación y del tráfico". Ante ello, señala, "surge la necesidad práctica de crear organizaciones capaces de acción política en un plano supranacional" (Habermas, 1999: 131). Si bien advierte sobre la necesidad de fortalecer el vínculo entre soberanía popular y las estructuras "burocráticas" de la UE, Habermas no tiene dudas de que la superación del Estado nacional tiene en la UE un plausible y ejemplar modelo. "Los europeos", indica, "han aprendido en las catástrofes de dos guerras mundiales que tienen que superar aquellas mentalidades en las que enraízan los mecanismos nacionalistas de exclusión" (Habermas, 1999: 133).

Para Habermas, el Estado- nación no va a recuperar su fuerza mediante una "política de atrincheramiento" pero, añade, "tampoco resulta convincente una política de autoliquidación del Estado en la que éste se desvanece en redes posnacionales. Y propone una "estrategia" mediante "el proyecto de una política transnacional que amarre y limite las redes globales", algo que, reconoce, "suscita la paradójica expectativa" de que los Estados- nación tienen "perseguir" desde hoy, y "dentro de sus actuales posibilidades de acción" un programa de acción "que solo puede realizar más allá de sus fronteras" (Habermas, 2000: 108- 109). Habermas se sitúa en una posición intermedia, posibilista, entre los extremos de quienes "preconizan el cierre de la sociedad" y quienes alaban una apertura sin límites autoproclamándose "progresistas". Se requiere, dice, un "auténtico equilibrio entre apertura y clausura que ha caracterizado las etapas más afortunadas de la modernización europea". Y para ello analiza las "condiciones para una política democrática más allá del Estado- nación" tomando a la UE como modelo por ser "la primera configuración de una democracia posnacional" (Habermas, 2000: 117- 118).

En este escenario la ciudadanía postnacional se cimienta en la participación política de los individuos: "El orden democrático no depende originariamente de su arraigo mental en la "nación" considerada como una comunidad de destino prepolítica. El punto fuerte del Estado constitucional democrático consiste en poder tapar los huecos que deja la integración social mediante la participación política de los ciudadanos" (Habermas, 2000: 103).

\section{DEBATE SOBRE LA TITULARIDAD DE LOS DERECHOS POLÍTICOS POR PARTE DE LOS INMIGRANTES Y LA IDEA DE CIUDADANÍA}

Sobre la pertinencia y la justicia de reconocer la titularidad de derechos políticos a los inmigrantes, con el derecho de sufragio como centro, no existe un consenso en los 
ordenamientos jurídicos nacionales, ni siquiera en lo que a los ordenamientos jurídicos de los países miembros de la UE se refiere. Y es que aún no se ha encontrado un modelo plenamente eficaz que dé la respuesta adecuada al fenómeno migratorio por lo que aún existen graves disfunciones en los procesos de integración (Ortega Giménez, A., 2009). Ello, a pesar de definiciones de pensadores reconocidos como Ferrajoli para quien los derechos fundamentales son todos aquellos derechos subjetivos que corresponden universalmente a "todos" los seres humanos en tanto dotados del estatus "de personas, o de ciudadanos o de personas capaces de actuar" (Vitale, 2002: 43). La Declaración Universal de Derechos Humanos (DUDH) es demasiado genérica en este terreno no obstante su singular y extraordinario aporte para el avance para el respeto de los derechos humanos. En cualquier caso, tal como señala Ortega Giménez, A. (2014), bloques como el de la UE se enfrentan al reto de construir una política generosa, proactiva y comunitaria en inmigración mediante un modelo jurídico común en materia de integración de la población inmigrante, elemento esencial para la deseada política europea común de inmigración.

Hay autores que opinan que todos los inmigrantes deberían tener derecho al voto y en todo tipo de elecciones, incluyendo las generales. En esta línea Méndez (2005: 126-127), por ejemplo, considera que al no reconocer el derecho de sufragio a los inmigrantes se está dejando a este numeroso colectivo al margen de la toma de decisiones sobre asuntos públicos, algo que no es deseable ni para los inmigrantes ni para la sociedad de acogida. En la misma línea Aja y Moya (2008: 66) hacen un paralelismo entre lo que acontece actualmente en torno al reconocimiento del derecho de sufragio a favor de los inmigrantes y el recorrido histórico del derecho del sufragio en sí mismo desde su inicial concesión discriminatoria a favor únicamente de determinadas clases sociales y de los varones hasta la extensión "universal" al menos para todos los nacionales de un determinado país. Andrés (2008) defiende igualmente que, de la misma forma como se exige a los inmigrantes el cumplimiento del ordenamiento jurídico del país de acogida, resulta lógico reconocerles el derecho al voto como cimiento esencial de la democracia futura. Aja y Moya (2008: 67), recuerdan que es muy significativa la posibilidad que introduce el artículo 16 del Convenio Europeo de Derechos Humanos de establecer "restricciones a la actividad política de los extranjeros". Ortega Giménez, A. (2014) destaca la necesidad de sentar las bases para una adecuada política comunitaria en materia de inmigración que propicie la integración de extranjeros, mediante un modelo jurídico común a los Estados miembros de la Unión Europea y que descanse en pilares entre los que se encuentra el reconocimiento de derechos y libertades al extranjero y su no criminalización.

Respecto de los derechos de participación distintos al del sufragio, Moya y Viñas (2010: 27) indican que ha sido su conexión con los derechos civiles, laborales y sociales lo que ha facilitado su progresiva extensión "en el ámbito de los inmigrantes". Recuerdan que el Estado liberal ha reconocido "en general" los derechos civiles a los extranjeros. Posteriormente se han ido reconociendo a favor de los inmigrantes los llamados derechos sociales y laborales. Extensión que en la segunda mitad del S.XX ha arrastrado a derechos como los de asociación, reunión, manifestación, sindicación o huelga al calor de la legislación internacional alumbrada tras la Segunda Guerra Mundial.

Una gran parte de autores que analizan la materia coinciden en líneas generales en la necesidad y en la justicia de reconocer que los inmigrantes son titulares de los derechos civiles y políticos elementales. Sin embargo, persisten dudas sobre el reconocimiento de la titularidad a favor de los inmigrantes del derecho de sufragio.

Arango y Sandell abogan por el reconocimiento del derecho al voto de los inmigrantes en todo tipo de elecciones. En este marco señalan que "el reconocimiento de derechos es uno de 
los pilares básicos de la integración" apuntando que por regla general "los inmigrantes están sujetos a las mismas obligaciones que los ciudadanos autóctonos". Añade que las limitaciones de los derechos políticos y sociales "hacen a estos más vulnerables" e "institucionalizan diferencias entre los inmigrantes y los demás ciudadanos" con el riesgo de dar pie a una marginalidad "con importantes repercusiones para el conjunto de la sociedad". El hecho de que los inmigrantes tengan reconocido el derecho al voto propicia que estos ciudadanos se hagan "corresponsables de la sociedad en la que viven". Dependiendo del tiempo de residencia de los concernidos, continúan, a largo plazo "se debería aspirar a que muchos inmigrantes pudieran participar en las elecciones generales, alentándoles a solicitar la nacionalidad española y considerando la posibilidad de extender este derecho a los residentes permanentes" (Arango y Sandell, 2004: 47- 48).

Para Borja (2014: 177), todas las personas son titulares de los derechos civiles mientras que solo "los nacionales" y, entre ellos, "únicamente" los que "tienen la calidad de ciudadanos" son titulares de los derechos políticos en el marco de la fusión conceptual que este autor evidencia entre los términos de ciudadanía y nacionalidad.

Por su parte Torres del Moral (2010:34) señala que "sólo recientemente los países jurídica y políticamente más avanzados adoptaron estándares mínimos de derechos para los extranjeros" para reconocerles, al menos, aquellos derechos considerados inherentes al ser humano. Ese nivel mínimo, indica el autor (lo que se ha llamado estándar mínimo internacional), coincide con la DUDH siguiendo a la profesora Elisa Pérez Vera. En cualquier caso, la tendencia internacional, anota, "es la de ir ampliando los derechos y las garantías de los extranjeros reconociéndoles los derechos civiles y, en ocasiones, bajo ciertas circunstancias, también los derechos políticos".

En torno a lo que jurídicamente se establece como clasificación tripartita de los derechos fundamentales de los extranjeros en España, Mora (2013: 593) recuerda que el TC, mediante la STC 107/1984, estableció el marco del llamado estándar mínimo internacional: los derechos que pertenecen por igual a españoles y extranjeros; los que no pertenecen en modo alguno a los extranjeros, y aquellos otros que pertenecerán o no a los extranjeros según dispongan los tratados y las leyes. En torno a la implicación concreta de la citada clasificación tripartita y refiriéndose a los derechos políticos y al derecho al sufragio en particular que "de ninguna manera pertenecen a los extranjeros", Triguero (2008: 58) señala que lo que produce esta taxativa negación es que los extranjeros se identifican de forma clara y manifiesta con la condición de trabajadores, gozando así de un conjunto de derechos y beneficios sociales pero carecen de la identidad colectiva que les reportaría disfrutar del conjunto de derechos de ciudadanía política, creándose un grupo en la sociedad que disfruta de derechos sociales y civiles pero no de derechos políticos y dando lugar así a una "situación de extranjería permanente".

En esta última frase Triguero alude al concepto acuñado por Benhabib y Zadunaisky (2005). El autor subraya, sin embargo, que el derecho de sufragio, "en principio tajantemente prohibido" para los extranjeros presenta una excepción notable según el artículo $13 \mathrm{CE}$ : el derecho de sufragio en elecciones municipales queda supeditado a la firma de convenios o acuerdos de reciprocidad internacionales. En este marco en España, como miembro de la UE, votan en comicios locales y en los del Parlamento Europeo los nacionales del resto de países miembros de la UE. Y, desde la suscripción de acuerdos bilaterales también votan en España los inmigrantes nacionales de los países correspondientes, la mayoría latinoamericanos, tal como se analiza en este trabajo.

La CE consigna en su artículo 13.1 que los extranjeros "gozarán en España de las libertades públicas que garantiza el presente título (el Título I) en los términos que 
establezcan los tratados y la ley". El TC afirma que esa expresión de libertades públicas no tiene aquí un significado técnico y restrictivo, sino amplio, equivalente a derechos y libertades. Si esto es asumido así, señala Torres del Moral (2010: 344), la igualdad o la desigualdad en la titularidad de derechos y libertades dependerá de lo que en cada caso dispongan la Constitución, los tratados y las leyes (STC 107/1984, de 23 de noviembre). El autor advierte de que "no queda totalmente desconstitucionalizado el estatuto jurídico del extranjero pues sus derechos no pueden ser otros distintos de los que garantiza el título I de la Constitución".

Y es que, como recuerda Méndez (2005: 126-127), el derecho de sufragio activo y pasivo ha permanecido legalmente asociado al requisito de la nacionalidad según el cual sólo las personas que ostentan la nacionalidad de un Estado forman parte de su comunidad política y tienen derecho a tomar parte en las decisiones públicas a través del sufragio. Méndez advierte de que el resultado de que los inmigrantes no tengan reconocido el derecho de sufragio deriva en que estas personas "permanecen al margen de la toma de decisiones sobre asuntos públicos, no "cuentan" y no son "tenidos en cuenta". Porque, considera, el reconocimiento del derecho de sufragio implica que los individuos concernidos se sientan partícipes de una comunidad política tomando parte en la toma de decisiones colectivas y en la configuración, claro está, del marco legal que afecta a sus vidas.

La realidad transnacional de los últimos decenios establece clasificaciones en este marco que se centran en la redefinición de los derechos de ciudadanía de inmigrantes y emigrantes (Emmerich y Peraza Torres, 2011). En cuanto al concepto de participación civil y política en lo que a los extranjeros se refiere, De Lucas et al., (2008: 105) consideran que hay dos tipos de criterios para catalogar la participación de los inmigrantes señalando que el término participación hace referencia a la participación política mediante el derecho de sufragio y/o la actividad de los partidos políticos, y a la participación cívica, entendida como la implicación en la vida asociativa y en los mecanismos y canales institucionales de participación (p. 105).

Autores como Strohmayer, et al., (2005) si bien apuntan que existen otros caminos de participación ciudadana y se cuenta con amplia bibliografía sobre la creación de estructuras, sobre todo a nivel local, especialmente ideadas para integrar en las decisiones políticas y comunitarias a los inmigrantes, tal como las que proponen entidades que trabajan directamente con colectivos inmigrantes, es un hecho que el reconocimiento de la titularidad y del ejercicio de los derechos civiles y políticos en sentido estricto y con las precisiones legales de los ordenamientos jurídicos internacional y español es vía esencial en los procesos de integración. En este marco el derecho al sufragio se erige como elemento básico de integración y participación política.

El debate sobre la necesidad, la pertinencia o incluso la justicia de reconocer a los inmigrantes el derecho de sufragio encuentra cada vez más adeptos entre quienes se inclinan por la extensión de tal derecho entre los nuevos vecinos de la misma manera como este derecho fue reconocido paso a paso a lo largo de los últimos siglos a favor de quienes carecen de propiedades, de las mujeres y de personas de razas determinadas anteriormente excluidas, como sucedió en Estados Unidos.

Esta corriente que defiende un reconocimiento de la titularidad de los derechos políticos en su plenitud encuentra en autores como Moya y Viñas (2010: 21- 22) una manifestación que resume el escenario. Estos autores destacan que en la mayor parte de países europeos existe la premisa ampliamente compartida de que "la plenitud de derechos políticos se alcanza con la adquisición de la ciudadanía" que, sin embargo, en la mayor parte de Estados se equipara legalmente, aun hoy, con la nacionalidad. Sobre la opinión de autores que no ven claro el reconocimiento a favor de los inmigrantes de la titularidad de derechos como el de 
sufragio, Aja y Moya (2008: 66) responden abordando lo que califican como rechazo tradicional a los derechos políticos de los extranjeros con un breve apunte histórico que enlaza con la historia que en general han vivido los derechos políticos $\mathrm{y}$, concretamente, el derecho de sufragio en su extensión entre los diferentes colectivos. Así, indican que "la razón última de la limitación de los derechos políticos a los inmigrantes es la misma que explica su azarosa trayectoria en el Estado liberal-democrático". Recuerdan que el derecho de sufragio no llegó a ser universal en muchos países sino hasta que así lo determinaron las constituciones posteriores a las dos guerras mundiales.

\section{CIUDADANÍA IBEROAMERICANA Y EXTENSIÓN DEL DERECHO DE SUFRAGIO}

La colectividad formada por los latinoamericanos residentes en España resulta hoy por hoy un elemento que adquiere cada vez mayor relevancia en la escena social y política de España. Entre 2002 y 2012 se concedió la nacionalidad española a 611.897 latinoamericanos entre argentinos, bolivianos, brasileños, chilenos, colombianos, costarricenses, cubanos, ecuatorianos, salvadoreños, hondureños, mexicanos, nicaragüenses, panameños, paraguayos, peruanos, dominicanos, uruguayos, venezolanos y latinoamericanos de otras nacionalidades. Sumando estas cifras a las del número de latinoamericanos residentes en España (aquellos que no se han naturalizado como españoles) se puede inferir que aproximadamente más de dos millones de latinoamericanos residen en España, nacionalizados como españoles o no naturalizados como tales (Secretaría General de Inmigración e Inmigración del Ministerio de Empleo y Seguridad Social, 2014). Zorogastua Camacho (2016) destaca que el 75\% de inmigrantes en España proceden de Europa y de Latinoamérica, y que el hecho de que gran parte de inmigrantes procedan de Latinoamérica es un factor que ha facilitado la integración en el país por el hecho de compartir valores occidentales, una lengua común y un deseo de buscar oportunidades, manteniendo una convivencia positiva a pesar de la profunda crisis económica que azota España desde 2008.

En este contexto, el concepto de ciudadanía postnacional, conforme al razonamiento de Habermas, de la misma forma como da fundamento y explica la ciudadanía de la UE igualmente puede fundamentar perfectamente la idea de ciudadanía iberoamericana. Una conceptualización que, al igual que la de la ciudadanía europea, viene siendo desarrollada legislativamente desde hace más de medio siglo por tratados internacionales y leyes nacionales.

La propia CE da pie y legitima esta formulación al señalar en su artículo 56.1 que una de las funciones del rey es la de asumir "la más alta representación del Estado español en las relaciones internacionales, especialmente con las naciones de su comunidad histórica". Comunidad histórica que no es otra que la comunidad iberoamericana. Induciendo, pues, la ciudadanía postnacional es la ciudadanía lo más cercana posible en nuestros días a la idea del cosmopolitismo estoico; ante las evidentes dificultades de contar con la ansiada y seguramente utópica (al menos por el momento) ciudadanía universal se forman bloques que, como la UE, permiten una ciudadanía entre miembros de una comunidad política, la propia UE, y, como argumentamos, entre miembros de una histórica y cultural como la comunidad iberoamericana , plasmada en la propia $\mathrm{CE}$, que señala que España podrá celebrar acuerdos de doble nacionalidad con países iberoamericanos (artículo 11), y que habla de la comunidad histórica española en clara referencia a la comunidad iberoamericana (artículo 56). Una realidad que, además, está legitimada por los especiales vínculos entre España y 
Latinoamérica, tal como existe un trato preferente en otras comunidades internacionales como el que, por ejemplo, permite que el Reino Unido tenga un trato privilegiado a nivel legal con el resto de países que forman la British Commonwealth of Nations.

La vinculación legal hispano-latinoamericana lleva décadas forjándose. Uno de los puntos más relevantes en este aspecto es que la mayor parte de países latinoamericanos tienen suscritos con España convenios de doble nacionalidad. A saber, 21 de los 24 países con los España tiene suscritos convenios de esta naturaleza con latinoamericanos: Argentina, Bolivia, Brasil, Chile, Colombia, Costa Rica, Cuba, República Dominicana, Ecuador, Guatemala, Honduras, México, Nicaragua, Panamá, Paraguay, Perú, Portugal, Puerto Rico, El Salvador, Uruguay y Venezuela. Los otros tres países que integran la lista son Andorra, Guinea Ecuatorial y Filipinas (Ministerio de Empleo y Seguridad Social, 2014; Ministerio de Justicia, 2014). En general, el punto de partida del reconocimiento del derecho de sufragio a favor de los residentes no nacionales en el caso de España nace a partir de la aplicación del Tratado de Maastricht con el fin de que los nacionales de otros países de la UE puedan elegir y ser elegidos en comicios locales. Posteriormente se ha reconocido el derecho de sufragio a nacionales de países europeos no comunitarios como Noruega y Suiza. En 2009 se da un paso cualitativo en este marco pues España empieza a firmar acuerdos de reciprocidad en materia de sufragio con países que no pertenecen ni a la UE ni a Europa y que son los que han permitido que voten en comicios locales personas no comunitarias en comicios locales a partir de la susodicha cita electoral de 2011. Acuerdos que, naturalmente, cumplen con la exigencia de reciprocidad, conforme marca la Constitución Española.

Así pues, en este contexto sobresale el hecho de que si hablamos de bloques geográficos o regionales, la mayor parte de los países que han suscrito tales acuerdos con España son latinoamericanos. Una situación que no es casual sino que se basa en la identidad cultural e histórica, que da pie a que los flujos migratorios hispano-latinoamericanos se enmarquen en un concepto de integración destacable, y que tributa en el hecho de que la mayor parte de países latinoamericanos han avanzado en la senda democrática en los últimos años, por lo que se puede cumplir con la exigencia de reciprocidad que señala el artículo 13 de la CE.

Hasta la fecha han sido dos las ocasiones en las que tales convenios se han podido llevar a la práctica en elecciones en España: los comicios locales celebrados el 22 de mayo de 2011 y el 24 de mayo de 2015. En ambas ocasiones, el número de inmigrantes latinoamericanos que efectivamente ejercieron su derecho a voto en el marco de los mencionados convenios de reciprocidad en materia de sufragio fue exiguo si se compara con las expectativas y con el número de personas que cumplían con los requisitos para poder ejercer tal derecho. Una serie de exigencia plasmadas en legislación interna (órdenes ministeriales, principalmente), propiciaron dificultades como el hecho de que a quienes quieran acogerse a tales convenios se les obliga a inscribirse para cada proceso electoral en el Censo de Electores Residentes en España (CERE). Un tema que merece un análisis detallado e independiente de este artículo.

\section{CONCLUSIONES}

El concepto de ciudadanía ha pasado de basarse en una idea excluyente - los ciudadanos se definían por aspectos de los que otras personas carecían- originada en la Grecia clásica mediante la que únicamente eran ciudadanos las personas que ostentaban determinadas categorías (varones, propietarios, etc.), reafirmado con matices incluso por los autores y las sociedades en torno al discurso de Marshall, a una idea incluyente desligada del concepto de nacionalidad en muchos sentidos que señala que pueden ostentar la condición de ciudadanos 
determinados extranjeros residentes en un país sin que se les exija adoptar la nacionalidad del país en cuestión, lo que les abre las puertas para ejercer incluso el derecho político por antonomasia, cual es el derecho de sufragio. Derecho este último que ejemplifica como pocos la evolución del concepto de ciudadanía a lo largo de la historia partiendo de una noción excluyente llegando a lo que hoy en día podemos calificar como concepto esencialmente incluyente. El reconocimiento de la titularidad y el ejercicio del derecho de sufragio, en este contexto, ha ido ampliándose progresivamente de modo que incluye a todos los varones, a los propietarios, a las mujeres y, en la actualidad, poco a poco, a los inmigrantes que, eso sí, aún deben cumplir con determinados requisitos.

La democracia mantiene sus imperfecciones y en ella, finalmente, lo posible prima sobre lo utópico. Las conceptualizaciones más audaces sobre ciudadanía cosmopolita pueden degenerar en autoritarismo o en utopías de gobiernos colectivos en la medida en que impondrían a los ciudadanos el ejercicio político. El derecho político por antonomasia, cual es de sufragio, por su propia naturaleza es un derecho facultativo, probablemente también el derecho facultativo por antonomasia; la participación política se basa en que los ciudadanos son libres de ejercerla o no respetando la naturaleza esencialmente facultativa de derechos como el de sufragio.

En esta línea por sus componentes realistas y posibilistas la idea de ciudadanía postnacional que desarrolla conceptualmente Habermas se acerca a la idea de ciudadanía lo más cercana posible al ideal de bien común sin dejar de lado al individuo.

El pragmatismo obliga a adoptar una postura intermedia entre la posición quimérica de quienes defienden que todos los inmigrantes e incluso todos los extranjeros deben ser titulares de todos los derechos políticos en el país en el que se encuentren y quienes niegan todos los derechos políticos a todos los inmigrantes. El concepto que sustenta la ciudadanía postnacional, desarrollado por Habermas, es el que se erige no sólo como posible sino también como óptimo pues permite articular espacios en los que oriundos y originarios de otros Estados comparten elementos de ciudadanía política en virtud de condiciones y/o legítimos intereses comunes, algo de lo que la ciudadanía de la UE es el mejor exponente.

La ciudadanía europea es el paradigma del concepto de ciudadanía postnacional. De igual manera, en la práctica se está gestando lo que bien puede denominarse como ciudadanía iberoamericana teniendo como base acuerdos suscritos entre España y la mayor parte de países latinoamericanos que permiten que los latinoamericanos en España y los españoles en Latinoamérica disfruten de derechos de ciudadanía entre los que destaca el derecho político por antonomasia, cual es el derecho de sufragio. Merced a convenios que llevan décadas en vigor, como los acuerdos de doble nacionalidad y, más recientemente, los acuerdos de reciprocidad en materia de sufragio en comicios locales, se configura una ciudadanía iberoamericana cimentada en los vínculos históricos y culturales hispano-latinoamericanos.

\section{BIBLIOGRAFÍA}

Aja, E. y Moya, D. (2008) "El derecho de sufragio de los extranjeros residentes". En E. Aja, J. Arango y J. Olivier (Dirs.) La inmigración en la encrucijada. Anuario de la Inmigración en España CIDOB. Barcelona: Bellaterra, pp. 64-81.

Andrés, H. (2008) "El derecho de voto de los extranjeros en el ámbito universal". Revista de Derecho Migratorio y Extranjería, (18): pp. 9-43.

Arango, J. y Sandell, R. (Eds.) (2004) Inmigración: prioridades para una nueva política española. Madrid: Real Instituto Elcano, disponible en goo.gl/AN2QY2 (26/03/2017) 
Aristóteles (2000) Política. Madrid: Gredos.

Benhabib, S. y Zadunaisky, G. (2005) Los derechos de los otros: Extranjeros, residentes y ciudadanos. Barcelona: Gedisa.

Borja, R. (2014) Enciclopedia de la Política. México: Fondo de Cultura Económica, disponible en goo.gl/lVfc0i (26/03/2017)

De Lucas, J.; Añón, M.J.; Galiana, Á.; García, J.; Mestre i Mestre, R.; Miravet, P.; Ruiz, M.; Simó, C.; Solanes, Á. y Torres, F. (2008) Los derechos de participación como elemento de integración de los inmigrantes. Bilbao: Fundación BBVA.

Durán Ayago, A. (2015) "Ciudadanía democrática vs. identidad nacional: los derechos políticos de los extranjeros en España”. Barataria. Revista Castellano-Manchega de Ciencias Sociales, (19): 85101.

Emmerich, G. y Peraza Torres, X. (2011) "Sufragio transnacional. Experiencias latinoamericanas de voto desde el exterior y voto de los extranjeros". IV Congreso de la Red Internacional de Migración y Desarrollo. Quito, Ecuador, disponible en: goo.g1/9LJaz2 (26/03/2017)

Giner, S.; Lamo de Espinosa, E. y Torres, C. (1998) Diccionario de Sociología. Madrid: Alianza Editorial.

Güell, E. (2014) Ciudadanía y mundialización. Barcelona: Universidad Pompeu Fabra, disponible en goo.gl/Xi10aP (26/03/2017)

Habermas, J. (1999) La inclusión del otro. Estudios de teoría política. Buenos Aires: Paidós.

Habermas, J. (2000) La constelación posnacional. Buenos Aires: Paidós.

Habermas, J. (2007) Identidades nacionales y posnacionales. Madrid: Tecnos.

Habermas, J. (2010) Facticidad y validez. Sobre el derecho y el estado democrático de derecho en términos de teoría del discurso. Madrid: Trotta.

Heater, D. (2007) Ciudadanía. Una breve historia. Madrid: Alianza.

Hobbes, T. y Mellizo, C. (2000) De Cive: elementos filosóficos sobre el ciudadano. Madrid: Alianza Editorial.

Horrach Miralles, J.A. (2009) "Sobre el concepto de ciudadanía: historia y modelos". Factótum, 6:1-22, disponible en: goo.gl/LtxDH1 (26/03/2017)

Izquierdo, A.; López de Lera, D. y Martínez-Buján, R. (2002) "Los preferidos del siglo XXI: la inmigración latinoamericana en España”. En F.J.G. Castaño y C-M. López (Eds.) La inmigración en España: contextos y alternativas. Granada: Laboratorio de Estudios Interculturales de la Universidad de Granada, pp. 237-249.

Kant, I. (2003) La paz perpetua. Biblioteca Virtual Universal, disponible en goo.gl/e6MUWz $(26 / 03 / 2017)$

Marshall, T.H. (1997) "Ciudadanía y clase social”. Revista Española de Investigaciones Sociológicas, 79: $297-344$

Martínez de Pisón, J. (2004) "¿Tienen derechos los inmigrantes? Derechos humanos y procesos migratorios: paradojas y posibilidades". Jornadas sobre los inmigrantes como nuevos actores del desarrollo. Globalización, migración y derechos. Valencia: Universidad de Valencia.

Méndez Lago, M. (2005) "Los derechos políticos de los inmigrantes”. En M. Hernández y A. Pedreño (Eds.) La condición inmigrante: exploraciones e investigaciones desde la región de Murcia, pp. 125-140, disponible en goo.gl/S4Nd7J (26/03/2017)

Ministerio de Justicia (2014) Convenios de doble nacionalidad, disponible en: goo.gl/x14512 $(26 / 03 / 2017)$

Mora Alemañy, R. (2013) “¿También los extranjeros son iguales ante la ley?”. Revista de Derecho de la Universidad Nacional de Educación a Distancia, 12: 561-594, disponible en: goo.gl/yKUouA $(26 / 03 / 2017)$

Moya, D. y Viñas, A. (2010) Sufragio y participación política de los extranjeros extracomunitarios en Europa. Barcelona: Fundació Carles Pi i Sunyer.

Ortega Giménez, A. (2009) "Reino Unido. Pluralidad racial e integración de las minorías étnicas en Reino Unido", en R. Tur Ausina (Dir.) La integración de la población inmigrante en el marco europeo, estatal y autonómico español. Madrid: Iustel, pp. 151-180. 
Ortega Giménez, A. (2014) "Hacia la construcción de un modelo común de la integración de la población inmigrante en la Unión Europea", Colección Cuadernos del Observatorio de la Inmigración de la Ciudad de Elche, $\mathrm{n}^{\mathrm{0}}$ 1, Valencia: Editorial Tirant lo Blanch.

Renan, J. E. (1987) ¿Qué es una nación? Madrid: Alianza Editorial.

Rodríguez Ruiz, B. (2015) "Participación y ciudadanía más allá del sufragio. Los derechos de participación de las personas extranjeras". Revista de Estudios Políticos, 169: 45-74.

Santolaya, P. y Díaz-Crego, M. (2008) El sufragio de los extranjeros: un estudio de derecho comparado. Madrid: Centro de Estudios Políticos y Constitucionales.

Strohmayer, H.; Carrasquilla, M-C. y Seidel, S-E. (2005) "Vía para la integración de las personas Inmigrantes. Rutas y caminos". En M-C. Carrasquilla y S-E. Seidel (Eds.) La participación ciudadana. Murcia: Nexos.

Torres del Moral, A. (2010) Principios de derecho constitucional español. Madrid: Universidad Complutense de Madrid.

Triguero, L. (2008) El estatuto jurídico laboral del trabajador extranjero inmigrante. Albacete: Bomarzo.

Unión Europea (1992) "Tratado de la Unión Europea", Maastricht el 7 de febrero de 1992. Versión consolidada, Diario Oficial de la Unión Europea, 191: 1-112, disponible en: goo.gl/L64s1B $(26 / 03 / 2017)$

Uribe Otalora, A. (2019) Votos y vetos: el derecho de sufragio de los inmigrantes en la Unión Europea. Madrid: Temas del Senado.

Vitale, E. (2002) "Reflexiones sobre el paradigma de los derechos fundamentales". Isonomía, 16: 3952, disponible en: goo.gl/rs7I8Y (26/03/2017)

Zorogastua Camacho, J. (2016) "El modelo español de integración de inmigrantes y la posible incidencia de una apertura en su política de refugio" en Migración y asilo: nuevos retos y oportunidades para Europa. Cizur Menor: Editorial Aranzadi.

\section{Breve currículo:}

\section{Yolanda Carmela Vaccaro Alexander}

Comunicadora Licenciada por la Universidad Complutense de Madrid. Corresponsal de El Comercio, el diario líder en Perú, y Consultora del Banco Interamericano de Desarrollo. Ha realizado reportajes en Europa y Oriente Medio y entrevistado a personalidades como los presidentes Mariano Rajoy, José Luis Rodríguez Zapatero, José María Aznar y los Premios Nobel Mario Vargas Llosa, Muhammad Yunus, José Saramago y Kofi Annan. Participa en debates sobre actualidad en televisión y entidades como la Casa de América. Miembro en dos ediciones del Jurado de los Premios Internacionales de Periodismo Rey de España de la Agencia EFE. 